\section{Myth and the construction of meaning in mediated culture}

\author{
KOME - An International Journal of Pure \\ Communication Inquiry \\ Volume 1 Issue 2 p. 33-43. \\ (C) The Author(s) 2013 \\ Reprints and Permission: \\ kome@komejournal.com \\ Published by the Hungarian Communication \\ Studies Assoiciation
}

\author{
Salomé Sola Morales \\ Universidad Autónoma de Barcelona, Faculty of Communications Studies, Spain
}

\begin{abstract}
Traditionally mythical thought has been banished and considered less important than logical thinking. However, in the last decades several authors have claimed the need to revalorize this notion. From our perspective, myth is a key concept to explore the construction of meaning in media narratives. For instance, if we try to solve fundamental questions as what communication is or how media make meaning, we should take into consideration the epistemological scope of myth. This article's main objective is to prove that the co-implication between logos and mythos is essential to understand social communication and mediated culture. Thus, to avoid any kind of reductionism, it is necessary to establish a dialogue between the two forms of thinking and expression: the concept and the imagination.
\end{abstract}

Keywords: Myth, communication, mediated culture, ritual, narration

\title{
Introduction
}

This paper deals with the conceptualization of myth and its importance in the mediated culture. We propose a theoretical and analytical approach to myth, as a fundamental issue to understand the basis of social communication. First of all, we will try to make a conceptualization of the complex notion of myth and we will explore its particularities. This is supported, fundamentally, by the contributions of Mircea Eliade (1973), Joseph Campbell (1993), Kurt Hübner (1996), Lluís Duch (2002) and Hans Blumenberg (2003). Secondly, we will express the connection between myth, ritual and narrative, different questions that are crucial to understand mediated communication. Thirdly, we will underline the role of myths in everyday life and in the construction of identities. Fourthly, we will give special emphasis to the logo-mythical approach, a theoretical perspective that co-implicates mythos and logos, as two parts of the same process. And finally, we will highlight the theoretical importance of the mythological and the imagination in the study of mediated culture and communication. 


\section{Towards a conceptualization of the polysemic notion of myth}

Our main premise is that myth is not a simple reality because, as Mircea Eliade (1973, p. 18) has pointed out, it appears in very complex cultural contexts and never allows univocal and linear readings about it. This means that this notion can be interpreted from multiple and complementary perspectives. Indeed, from a psychological approach (Jung, 2011) myths are considered elementary ideas, while from a historical-ethnographic point of view they are called 'ethnic ideas' or 'popular ideas', as Joseph Campbell (1993) has suggested.

First of all we will refer to the particularities of myth and will follow the proposal of Lluís Duch, the Hispanic anthropologist who has best explored mythic structures to understand the human being. In one of his major works, Mito, interpretación y cultura (2002, p. 27), the author argues that myth comes to be present at all times and in all spaces, it must be constantly reinterpreted in terms of new variables that arise in the life paths of individuals and communities. Therefore, it has a particular importance in communication. The existence of a series of constants that prevail and transcend any whim makes us say that myth is a structural condition in human life. Or what is the same that all human beings are mythical by nature; and they use different myths -historical articulations- in different contexts or cultures.

As we consider a bit dogmatic to propose an ultimate and unique definition of the term, we will limit ourselves to a much more concrete work: we will try to describe the most important functions of myth that shed light to the understanding of media culture and communication.

It may be necessary to clarify that we presume that myths are theoretically 'multifunctional', as they are formed by different motivations (Duch, 2002, pp. 86-87). None of the particularities of the myths prevails and, if we observed them as a whole, they will allow us to understand the grammar and scope of myths in the mediated culture.

One of the first features of the concept under consideration is called by Duch, the communicative function. This aspect is crucial for us, because we understand myth as a search for meaning or as an attitude that demonstrates the polyphonic and imaginative capacity of the human being. Indeed, subjects and groups need different forms of expression that allow them to communicate their humanity which is, according to Duch, a complexio oppositorum. In this sense, myth, as Manfred Frank (1989) would say, tends to a mutual understanding of members of society and the harmony of their moral convictions.

The so-called by Duch (2002) teodiceica function is another key to understand the fundamental structure of myths. In fact, myths, with many different shapes, are related to the most important aspects of human life, but especially are related to the praxis of domination of the contingency (Lübbe, 1986). That is to say, these structures allow human beings face the problems and adapt themselves to changing situations always marked by temporality and human frailty. In other words, these practices help overcome the contingency to the extent that enable humans, individually, and groups, collectively, to move "from chaos to cosmos" (Duch, 2002, p. 37). In a sense, a therapeutic function could also be released, since myth, as religion, allows subjects (individual and collective) to take a place in the world. A social place configured by the media many times. A thinker who stressed this last therapeutic function is Hans Blumenberg (2003), who believes that mythical narratives are the mechanisms that enable man to overcome anxiety and the traps of an uncertain destiny.

Now, it is obvious that myth meets a set of cultural, religious and communicative functions, that offers comprehensive criteria to the different members of a culture; establishes hierarchies among individuals and groups, and draws and blurs the boundaries between the present and the absent, as Duch (2002) has pointed out. However, myths also perform historical and social functions: they speak about the origins and evolution of all types of 
societies. And these narrations also propose political functions that "serve the selfpresentation of consciousness of the identity of human communities" (Duch, 2002, p. 88). And this is essential to understand the configuration and circulation of the media collective imaginaries.

\section{How to interpret myths?}

When interpreting myths, there are several approaches for their better understanding. It would be worthwhile to devote some attention to two issues that are related to them: the narrative and the rituality.

In the light of the narrative perspective, myth is a communicative and experiential way that is submerged within the scope of the narration and not only in the mere description (Stolz, 1988). One of the authors that has adopted this approach is Blumenberg (2003, p.41), who has argued that myths are stories that have a high degree of constancy in their narrative core and also some margins of variation. In addition, myths express the complexity inherent in the reality of the world and the human. In fact, "what has become identified by their names is released from its bleak and strange character through metaphor, revealing, through storytelling, the meaning that encloses" (Blumenberg, 2003, p.41). At the same time, mythic narrative reveals the early crystallization of the experiences of communities. In other words, it does not only give meaning to the actions of individuals always and everywhere, but also, and mainly, to groups. In fact, mythical stories, in the same way that media stories, provide community members 'guidance' and information that allows them to be placed through an identification process (in the psychological sense).

From the perspective of the cult, myth and ritual are understood as processes that operate simultaneously. Actually, there are many anthropologists, among whom James Frazer can be highlighted, who imposed the view that myth and ritual were like two sides of the same coin: "The first would come to define the narrative sense (story) and the second, the representative and spectacular appearance (theater)" (Duch, 2002a, p. 183). In the same vein, Joseph Campbell (1993, p. 59) equates the link between the classic mind-body dichotomy and asserts: "Myths are the mental supports of rites; rituals are the physical representations of myths".

Although this concept has evolved and myth and ritual are now considered separate entities or processes (but complementary) we cannot forget that both have a very similar nature. So besides having a symbolic common basis, myth and ritual have also an essential psychological and emotional condition, which finds its rationale in the limits. As it is well known, the concept of limit has been studied in depth by Victor Turner (1988). For the British anthropologist, the fluidity of mythical narratives can be explained because of its liminal character. In fact, for him all liminal situations are happening in symbolic borders, and they include a series of concrete attitudes (individual and collective) that must be dramatized in front of the group members. From Turner's (1980) point of view, a ritual is a very stereotyped behavior and powerful in terms of cultural conventions, that communicates the more valuable social values, allowing participants to perform a role.

It is remarkable that the functioning of the ritual is similar to several media processes. In addition, myths tell how a situation led to another, how the world became populated, how chaos was transformed into cosmos, how the immortal turned into mortal, how seasons appeared in a climate where they did not previously exist (Turner, 1979, pp. 150-154). That is, myths explain the transformation processes, the transition from one situation to another, the intermediate steps that elapse between the one and the other or, what is the same, the vanishing points separating the unspeakable from the understandable. In "Myth and Symbol" 
(1979), Turner describes liminality as pure potentiality from which extra logical behaviors may arise, for even limits may be overridden or transcended.

All this leads us to believe that myth is a process or phenomenon that is substantially liminal. And it has the initiation of individuals as preliminary foundation; hence sometimes it works as a rite of passage. These processes are highly effective in an ontological level because the participants transform their situation or transcend their previous status to accept their new acquired position. Although, according to Turner, myths are not directly connected to specific rites, from our perspective they are related, in one way or in another, to a cultic practice, whether conscious or unconscious. And these theories are of particular interest for the study of mediated rituals and communication.

\section{Myths and quotidianity}

But besides having a direct link with cultic practices, myths are also an important part in cultural competences and represent a significant development in daily life. In this regard, Bronislaw Malinowski (1974) has placed particular emphasis on the scope of the mythical universes in everyday practice. In light of his ideas, myths are stories that deeply affect all society, and whose function is to justify or reinforce the beliefs and coding practices that articulate the life of a particular community. These processes are analogous to some of the functions of the media, like configuring beliefs, modifying practices and values or prioritizing ideas. All these phenomena are part of the mythical discourses and media discourses at the same time. And as Malinowski (1974, p. 124) stated: "Myth is not an idle fantasy, nor a meaningless outpouring of evanescent dreams, but a very laborious and extremely important cultural force".

This explains why myth is not used to amuse or entertain, but it has to be employed when a rite, ceremony or social or moral rule needs a justification, a guarantee of antiquity, reality or holiness (Malinowski, 1974, p. 131). The use of myth in these occasions, as guarantor of meaning of the groups, is closely related to the concept of tradition. In fact, myth strengthens tradition and gives value to the communication between generations. Therefore individuals can return to the origins or remember the past to resolve issues of present reality, using symbolic and mythical forms. Thus, it is clear that myths have an essential symbolic nature or, what is the same, that they use symbols to express their mission. Nor can we deny that media culture has a mythical and symbolic character if we consider the previous proposal.

Another of the key issues when addressing the scope of myth is its link to imagination. In this sense, the contributions of Gilbert Durand (1981) are highly relevant. Unlike Levi-Strauss (1979), for whom myth is a particular form of communication that can be assimilated into language, Durand believes that myth, instead of a notation that is translated or decrypted, is semantics presence and, being composed of symbols, it compressively contains its own sense (Durand, 1981, p. 340). In fact, as he has pointed out, myth does not translate, even in logic because any attempt to translate myth -as any attempt to move from the semantic to the semiotic- is an attempt to impoverishment (Durand, 1981, p. 341). From his view, what really matters about myth is not the thread of the story, but the symbolic meaning of the terms that appear on it, so that the translation itself is invalid. So, we should understand that the universe of myth is not founded on diachronic or synchronic relationships, but on comprehensive meanings. That is because it is a universe loaded by an immediate semantics and it can only be disturbed by the mediation of discourse. Thus, Durand is right when he claims an integrative view of the archetypical symbolic and mythical thinking modes, where imagination and reason are complementary. 
But perhaps the most interesting aspect of the study of myth is its epistemological and ontological scope. Actually, for us, there are issues that positive science and the hypotheticaldeductive method will never be able to solve. Indeed, the denial of imaginative and mythical forms has largely limited mere ontological description of the subject and the identifications that subjects and groups do in relation to media. It is important to remark that, for us, "myth can make an experiential basis to the above questions and could be 'effective' (symbolically) to give the somersault from the exoteric to the esoteric" (Duch, 2002, p . 89).

Because of this, we demand a renovative conception of myth, which allows overcome the dogmatic structure that privileges conceptualization, as the exclusive and absolute way to apprehend reality and configure human life (Duch, 2002, p. 430). And that after all, it does nothing but merely impoverish it. In this sense, it is necessary to revalorize the meanings and the imaginative and mythical way of understanding the reality and the communication. As Blumenberg (2003) has highlighted, myths have favored the reduction of a unique History, promoting several enriching and complementary meanings. Therefore myth can be proposed as a critical and alternative model, which would allow the opening to different and creative horizons. In that way, it will be possible to continue the hermeneutic path that is typical and necessary for human communication.

\section{The logo-mythic: a co-implication between mythos and logos}

The Western thought has been dominated throughout History, and even today in many areas, by separating metaphysical dichotomies. These irreducible antagonisms (among which may be cited as examples: essence-existence, reason-emotion, mind-body, image-concept, interior-exterior or mythos-logos) assume that among the above concepts or processes does not exist any kind of link or continuity. By contrast, Ernst Cassirer (1976, pp. 446-450) considers that only symbolic forms are capable of mediating between the dualisms of traditional thinking and experience of human beings. For us, as for Cassirer, the true concept of the symbolic cannot adapt to the traditional classifications or metaphysical dualism, but must overcome and break its frames. But obviously, this kind of categorical dichotomies forgets certain nuances, as the vast range of grays that is found between white and black. Moreover, these metaphysical divisions do not only separate the mentioned elements due to their differences, but give different value to them.

Thus, depending on the historical and cultural moment, one of the areas or concepts identified will be evaluated positively and the other relegated or even banished. To some extent, we could summarize the trend fluctuating between mythos and logos: when one held sway, the other ceased to exist. In fact, as Duch has proposed (2002, p.158), what has been attempted in Western culture has been that the logos replaces the mythos, as well as "the nous takes the place of the eros, the being (on) of the becoming (genesis), the eidos of the aisthesis, the essence of the existence, the act of the power, the definition of the intuition". And this supremacy of logos -as well as the supremacy of mythos-, as we will see, can have painful consequences.

But which are the reasons why myths, as the image or the existence, have been relegated from the positivist and traditional way of thinking? Some authors, such as Giambattista Vico (1995), who attributes a high degree of historical truth to the mythical tales, focused his criticism in cartesianism, whose prejudices against mythical thought we review briefly below. While we can say that Descartes was one of the most influential intellectuals in the creation of modern Western thought, we cannot forget that some of his paradigms have been installed coercively in some areas of reflection. During the seventeenth and eighteenth centuries his statements, along with other thinkers like Bacon and Newton, were erected against the 
mythical and mystical thought (Lévi-Strauss, 2002, p.124). And any type of speculation about myths was banished. The illustrated Science sought to eliminate all those 'subjective' elements like tastes, feelings, desires, moods, images or ethical provisions that are not susceptible of being verified. (Duch, 2002, p. 489).

At the same time, the value given by Descartes to logos (logocentrism) and the supremacy granted to the scientific technical method, led to the triumph of iconoclasm. In fact, according to Albert Chillón (2000, p. 141), the influence of the Cartesian paradigm is one of the reasons responsible for: "The longstanding iconoclasm professed by the Enlightenment, characteristic of modernity". Moreover, as suggested by Durand (1971), Cartesianism raised the triumph of the sign over the symbol, the concept over the imagination, because all Cartesians reject imagination, as well as feeling as phenomena that induce errors. It is interesting to recall that in the first part of the Discourse on Method, Descartes points to consider a fake everything that is not more than likely (Chillón, 2000, p. 141):

"After all, the Cartesian logocentrism extols the concept and postpones the image. In doing so he refuses to see, not only that the concept is born as an image and it needs images to function, but also that concept and image are the two aspects of the symbol. Also, that the distinguishing characteristic of human intellect is certainly the function of symbolization".

But it was not only Descartes who rejected the symbolic and mythical thought by attributing preponderance to reason; numerous authors, such as Sigmund Freud or James Frazer, also judged negatively the worlds of myth as wrong. And they argued that these worlds should be refuted, exceeded and finally replaced by Science (Campbell, 1993, p. 23). For these intellectuals, the relationship between mythos and logos was never dialectical. That is, there was never interaction or co-implication between them, but denial of one part for the benefit of the other. However, other researchers, as Blumenberg (2003, p. 20), emphasized that "the boundary line between myth and logos is imaginary". So we cannot accept a separation between these two ways of understanding reality, since both forms of expression cannot be canceled as they are complementary:

"Saying that the course of things has gone from myth to logos implies a dangerous ignorance, because one believes to be able to ensure that, at some point in the distant past, there was an irreversible leap forward that would have definitely left something [myth] behind" (Blumenberg, 2003, p. 35).

When, actually these two forms of expression must coexist. Precisely their coexistence is the basis of the mutual enrichment. This idea owes Cassirer's or Hübner's thought for whom there is no difference between the conceptual and the mythical, an opposition that the rationalist tradition had wanted to see, partly to maintain its hegemony and control. ${ }^{\text {ii }}$

However, we found various proposals that make us necessarily deconstruct logocentric logic from its own base. The epistemological paradigm of Thomas Kuhn (1962), for example, shows some of the limitations of Science and conceptual thinking. Besides, it allows us to manifest the inherent polysemy of each scientific discourse and the need to translate and interpret it within a particular tradition. From this perspective, any argumentation must be raised as a questioning of the reference system as Paul K. Feyerabend (1993) has suggested. From his point of view Science is sometimes closer to myths than it is prepared to admit. It is important to note that the author believes that reason and Science have displaced other beliefs, among which we could certainly include mythical thinking. This would indicate that logical thinking instead of been questioned or interiorized, is taken for granted very often. 
It should be remembered, therefore, that subjects appear in a host environment where there are already a number of unquestionable latent implications. Logics that function as cognitive frameworks, from which individuals and groups understand, define or delimit the surrounding world. Ortega y Gasset (1997) has given a metaphysical sense to these shared beliefs, since for him they form part of human life from the beginning. Here it is important to point out that the belief system cannot be individual or extracultural: hence it is conditioned by the media culture and cultural tradition in which an individual or group is inserted.

So another paradox that we find to address the dichotomy logos/ mythos (concept/ image) is the very difficulty of separating these two forms of expression and thought. In fact, in the mythical thought we can sometimes find a conceptual background and vice versa. In the same manner as in anthropology "emic" is also "etic", for instance.

Yet, paradoxically sometimes the creation of myths is perfectly rational -in the sense of economic rationality-. Such is the case of the McDonalization of the society proposed by George Ritzer (1993). This myth, a truly expression of capitalism, includes a series of symbols and characteristics that are similar to "pure" science like efficiency, calculation and falsation, uniformity and predictability or automation.

On the whole, from our perspective, it is necessary to establish a dialogue between the two forms of expression and communication. It is therefore necessary to build "bridges, mediations that bring us closer to things that remain in the ambit of distance or ignorance; and then get familiar with these things" (Duch, 2002, p. 153). Because if we meditate only in the domain of one of the spheres -the logic or the mythical- we would be accepting the rule of a dangerous single speech: the mono-discourse. All totalitarian discourse is based on the preponderance of one of these areas: the rational or the mythical. And as History has shown to us many times, the empire of one these spheres can have very adverse consequences. A mythical speech without critical consciousness -as the Holocaust, for example- or a logical discourse devoid of affection -as the worship to technology or market- becomes an aberration that destroy true humanity. In short, for us, mythos and logos are not two exclusive ways of existing or being in the world, but two different forms of expression that should be co-implicated and enhanced by each other.

\section{Myths, imagination and communication}

Actually, the complementarity or the co-implication between the two discourses is a comprehensive key to understand communication and one of the evidences of human multifacetism (Duch, 1984, pp. 247-332). A multifacetism that needs the word as an indispensable means of salvation, which drives human communication, and all forms of expression. Communication is the fundamental mission of the human being and his way of gaining knowledge about himself and others. A fact that highlights the need to implicate both the mythical and logical discourse, image and concept, imagination and abstraction.

Here it would be interesting to make an approach to the etymological origin of the word communication, which derives from the Latin comunicare (sharing or pooling) and the Greek кowvovía (communion). Two words that hint at the need to complicate and unite different approaches, among which we can mention, without any doubt, the logical and the mythical character of the human being.

Precisely the difference between communication and information, from our view, is based on this assumption. While communication provides a tension between the logical expression and the mythical, the mere information reduces the mythical to the logical. Thus, that is one of the reasons why we must understand the logo-mythic thinking as an essential anthropological and 
communicative praxis. Or, what is the same, as a necessity in our time, consisting in the renunciation of any kind of totalitarian discourse (Duch, 2002a, p. 501).

It is worth mentioning that the alleged commitment to rationality has caused many forms of "epistemological violence" (Teo, 2010). Precisely within social research, we can find logocentric interpretations that give a lower position to the subject observed. We are thinking, for example, of the contributions of Edward Said, who criticizes in Orientalism (2003), the ownership and definition -always reductive- of the Oriental by historians, writers and European travelers. All of them helped to create over time an indisputable scientific value based on impressions, prejudices and stereotypes.

But this kind of epistemological violence can also be seen in the discourse of the media that legitimates racism and social exclusion, for example, based on an alleged rhetoric of "objectivity". We are thinking of the countless news reports or television programs that associate migration or blackness with crime, for instance, or more recently Islam with terrorism. All this constructed "bad" news uses logic to create a myth about the other (in that case the foreigner, the immigrant). Theses TV reports or newspaper articles, as it is well known, are based fundamentally on police statistics or tests. And this is a fact that prevents or hinders a critical discourse or the answer of the receptors. The logic of tests constructs an irremediable "truth" that very few receivers can reject. Here it is very easy to see how a particular presentation of data in the media can become a common belief around people. And how this belief can transform into an irrational fear to the immigrants or Muslims, for example.

Like Science, Media (as an institution and a socialization agent) have a higher status than the theoretical criticism expressed by a marginalized other. In that way, the hegemonic discourse, stereotyped and exclusionary, can't be rejected or denied. And finally this mono-discourse ends up becoming an accepted reality, in a shared belief. Therefore by means of myth, conveyed by the media, it is possible to construct an admitted and shared logic.

However, not all communication is logical or responds to logical thinking. And here we are referring to the highly subjective and performative nature of all communicative exchange. From the enunciative communicative act to the mediated reception or virtual participation it is necessary to draw a path or "hermeneutic horizon" (Gadamer, 2007), that allows to create senses. And this subjective appropriation of reality and the message itself is based not only on the logic of logical meaning but also and mainly on the experience, namely in the sense arising from the intersubjective experience.

Here, it is important to consider imagination as a crucial category to understand both mythical forms of expression and the functioning of the media. As Chillón has noted (2000, p. 140) imagination is the psychic faculty par excellence, which, by means of configuration and synthesis, is ultimately responsible for all imaginable forms of insight and communication. It will be worthwhile to clarify this complex concept. We understand imagination, not as a special attitude or characteristic of some facets of existence (such as fantasies or dreams), but as the crucial psychical dynamic of all existence.

Furthermore, imagination is central to understand media culture (Duch and Chillón, 2012, pp. 235-292). That is because the construction of reality and the world in which the subjects and groups take place finds its way and its sense through imagination. Indeed, the human being configures the enigmatic world by "building things in themselves as phenomena, that is, as figures intelligible and communicable". (Chillón, 2000, p. 140). So we cannot forget the power of imaginaries and myths in the mediated culture. From our perspective, the narratives that appear in the media are configured thanks to some archetypal or stereotypical images. These are fundamental figures that appear in every story or media narrative -from the news to science fiction-. Recurrent images that give expression to common desires, unconscious fears or tensions that are above human conscious conduct (Campbell, 1959, p. 233). All these 
archetypical contents symbolize original and primary models and have a redundant character because they appear in all cultures always influenced by each social context or historical moment.

Finally it should be noted that particular traditions, through specific myths created and narrated by the media, provide consistency, fixation or rigor that create, at least, the sense of a community, the feeling of belonging or exclusion and the identity itself.

As it is well known, the images depicted in the media propose models about how to dress, move or respond to established standards of beauty. But under the yoke of these mirages, myths or ideal models largely unattainable, we can find serious psychological effects such as depression or eating disorders. Here, the interpretation of these images by receivers is very limited because there is nothing beyond the representation. These self-referential images are so explicit direct, that people apprehend them immediately. And don't give room to any question. However, we cannot forget that the pursuit of desire, pleasure and beauty are not new demands and, deep down, reveal the human struggle against the contingency.

Thus, to avoid communicative reductionism or imperialism -supremacy of one of the two areas studied-, our proposal, the logo-mythic, aims to reach the proper administration of human expressiveness and enhance the intersubjectivity as a specific version of human speech in its dual version of mythos and logos.

\section{Conclusions}

In short, we cannot forget that the mythical, expressed through specific myths and their interpretations, is a versatile and multifunctional presence in the lives of individuals and groups. That is because the logo-mythical expressions are complementary and help us achieve a more complete vision (although never final) of reality. In this regard, it is worth remembering that the symbol allows the union of these two spheres of thought and experience. In fact, the symbolic function is a combination of the two constituent dimensions of thought: $\log o s$ and mythos, reason and representation, concept and image, number and figure, analysis and synthesis, speech and narration (Chillón, 2000, p. 142).

On the whole, knowledge, the collective culture, the shared reality and moreover the individuals and groups behave in a symbolical way: they express and communicate figuratively or, what is the same, they use figurations to become intelligible. And this reality and its mediated forms of expression are fundamentally imaginative, as they are configured and created through symbolic forms and mythical narratives that constitute them.

Finally, mediated culture is one of these realities that are expressed in a mythopoetic way. This means that the media construct their stories in a mythical way: by using fables, stories, figurations and the imagination. But, what is the scope of the mythopoetic? As Ernst Cassirer (1976) has pointed out, this natural quality of language whose essence is mythical and metaphorical requires indirect ways of description. And the primary subjects of this language would be confusing or ambiguous terms that necessarily have to be interpreted symbolically. This ambiguity inherent in language, which we also see in the construction of identity or in communication, owes its origin to myth. Although myth is natural, it does not have to be related to the nature of external objects. In short, we cannot forget the value of the symbolic in creating identifications or transmitting beliefs, because symbols are created within human communities. And what is more important they function as cohesive elements that create ideology and images from each community. In conclusion, human being knows and builds everyday reality through symbols, myths, metaphors, and finally, mediations that are crucial to understand the communication and the influence of the media on individuals and groups. 


\section{Notes}

\footnotetext{
' The notion of complexio oppositorum, also called coincidence oppositorum or concordance of opposites was introduced by Nicholas of Cusa in the XV century and refers to the paradoxical state in which opposites coexist and where multiple aspects include a mysterious unity.

ii It is not difficult to notice that this supremacy allows delimiting several differences and grant contrary positions to the observer and the observed, for example.
}

\section{References}

Blumenberg, H., 2003. Trabajo sobre el mito. Barcelona: Paidós.

Campbell, J., 1959. El héroe de las mil caras. Psicoanálisis del Mito. México: Fondo de Cultura Económica.

Campbell, J., 1993. Los mitos. Barcelona: Paidós.

Cassirer, E., 1976. Filosofía de las formas simbólicas, Volumen 3: fenomenología del reconocimiento. Ciudad de México: Fondo de Cultura Económica.

Chillón, A., 2000. La urdimbre mitopoética de la cultura. Anàlisi. Quaderns de Comunicació i Cultura, 24, pp. 121-159.

Duch, Ll. and Chillón A., 2012. Un ser de mediaciones, Volumen 1. Barcelona: Herder.

Duch, Ll., 1984. Religió i món modern. Barcelona: Publicacions de l’Abadia de Monserrat.

Duch, L1., 2002. Mito, interpretación y cultura. Barcelona: Herder.

Durand, G., 1971. La imaginación simbólica. Buenos Aires: Amorrortu.

Durand, G., 1981. Las estructuras antropológicas del imaginario. Introducción a la arquetipología general. Madrid: Editorial Taurus.

Elíade, M., 1973. Mito y realidad. Madrid: Guadarrama.

Feyerabend, P. K., 1993. Against method. Verso: Londres.

Frank, M., 1989. Kaltes Herz-Unendliche Fahrt-Neue Mythologie. Motiv-Untersuchgen zur Pathogenese der Moderne, Farnkfut a. M., Suhrkamp.

Gadamer, H. G., 2007. Verdad y método. Salamanca: Ediciones Sígueme.

Jung, C. G., 2011. Arquetipos e inconsciente colectivo. Barcelona: Paidós.

Hübner, K., 1996. La verdad del mito. México: Siglo XXI.

Kunh, Th., 1962. The structure of scientific revolutions. The University of Chicago Press: Chicago.

Kunh, Th., 2000. The road since structure. The University of Chicago Press: Chicago.

Lévi-Strauss C., 2002. Mito y significado. Madrid: Alianza.

Lévi-Strauss, C., 1979. Antropología estructural. Madrid: Siglo XXI.

Lübbe, H., 1986. Religion nach der Aufklärung. Graz-Wien-Köln: Styria.

Malinowski, B., 1974. Magia, ciencia y religión. Barcelona: Ariel.

Ritzer, G., 1993. The McDonaldization of society: an investigation into the changing character of contemporary social life. Thousand Oaks, CA: Pine Forge Press.

Said, E. W., 1998. Orientalism. New York: Pantheon books. 
Stolz, F., 1988. Der mythische umgang mit den rationalitat und den rationale umgagng mit dem mythos. In: H.H. Schmid, ed. Mythos und rationalität. Gütersloh: Mohn, pp. 81-106.

Teo, T., 2010. What is Epistemological violence in the empirical social sciences? Social \& Personality Psychology Compass, 415, 295-303.

Turner, V., 1979. Mito y símbolo. In: D. L. Sills, ed. Enciclopedia Internacional de Ciencias Sociales, Volumen 7. Madrid: Aguilar, pp. 150-154.

Turner, V., 1980. Social dramas and stories about them. In: W. J. T. Mitchell, ed. On narrative. Chicago, IL: University of Chicago Press, pp. 137-164.

Turner, V., 1988. El proceso ritual. Madrid: Taurus.

Vico, G., 1995. Ciencia nueva. Madrid: Tecnos. 